\title{
SENSORY EVALUATION OF CAROTENOID AND PALM JAGGERY INCORPORATED FUNCTIONAL DRINK JIGARTHANDA
}

\author{
Revathi $\mathrm{P}^{1^{*}}$, Vasantha Esther Rani ${ }^{2}$
}

\footnotetext{
${ }^{1}$ Assistant Professor, Department of Food Science and Technology, Arul Anandar College (Autonomous), Karumathur, Madurai, Tamil Nadu, India ${ }^{2}$ Associate Professor and Head, Research Department of Home Science, Fatima College (Autonomous), Madurai, Tamil Nadu, India
}

Received - July 18, 2020; Revision - September 17, 2020; Accepted - January 03, 2021

Available Online - March 25, 2021

DOI: http://dx.doi.org/10.18006/2021.9(Spl-1-GCSGD_2020).S196.S201

\section{KEYWORDS \\ Functional drink \\ Jigarthanda \\ Carotenoid}

\section{* Corresponding author}

E-mail: revathi.rpr@gmail.com (P. Revathi)

Peer review under responsibility of Journal of Experimental Biology and Agricultural Sciences.

Production and Hosting by Horizon Publisher India [HPI] (http://www.horizonpublisherindia.in/).

All rights reserved.

\begin{abstract}
Functional foods are any fresh or processed food claimed to have a health-promoting or diseasepreventing property beyond the basic function of the supply of nutrients. Functional foods like beverages offer potential health benefits that could enhance the well-being of consumers and reduce the economic and social costs of treating non-communicable diseases. Jigarthanda is one of the best tasting summer drink which has its origins in Madurai. The present study was carried out on the development of the functional drink Jigarthanda incorporated with carrot and palm jaggery using basic ingredients such as milk, Kova, and almond gum. The functional drink was prepared with three variations viz., VI, VII, and VIII in two proportions i.e. A and B. In proportion A, all the three variations were incorporated with $100 \mathrm{ml}$ of carrot juice, and also VI, VII, and VIII contain $100 \mathrm{~g}, 150 \mathrm{~g}$, and $200 \mathrm{~g}$ of palm jaggery respectively. In proportion B all the three variations were incorporated with $200 \mathrm{ml}$ of carrot juice and also VI, VII and VIII contain $100 \mathrm{~g}, 150 \mathrm{~g}$, and $200 \mathrm{~g}$ of palm jaggery respectively. Among the three variations, in Variation I, all the sensory factors were marked high with the mean value of 7 in both Proportion A and B. In Variation II and Variation III, all the factors in both proportions, A and B were marked high with the mean score of more than seven, and particularly in variation III, the taste factor got a high mean score of more than 8 , and the overall acceptability was very high in Proportion B and the mean score was 7.3, which was more than the proportion A (7.27). Hence the functional drink Jigardhanda in VIII of Proportion B, which was made with 250gram palm jaggery, incorporated with $200 \mathrm{ml}$ of carotenoid-rich carrot juice obtained the highest overall acceptability score and was regarded as the best sensory evaluated variation of Jigarthanda. The popular traditional beverage Jigarthanda has been value-added by incorporating carotenoid-rich functional food to the consumers.
\end{abstract}

All the articles published by Journal of Experimental Biology and Agricultural Sciences are licensed under a Creative Commons Attribution-NonCommercial 4.0 International License Based on a work at www.jebas.org.

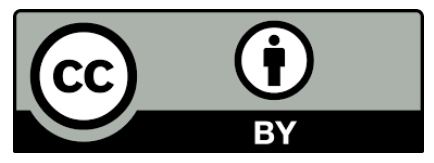




\section{Introduction}

Jigarthanda is one of the famous cold beverages in the South Indian city of Madurai in Tamil Nadu. Jigarthanda Drink (Jigar means Heart and Thanda means Cool) is a chilled beverage or drink, meaning "Cool Heart" in English. Hence it is the best drink for the hot summer. Milk, almond gum, sarsaparilla syrup, sugar, and ice-cream are the main ingredients used for the preparation of Jigarthanda.

As it is a sweet drink, Jigarthanda energizes the body. It has potentially beneficial effects because it contains milk, which has a range of bioactive components (Mounika \& Maloo, 2018). Further, almond gum and sarsaparilla syrup are natural body coolants. The almond gum is rich in protein and useful to boost male vitality, increase body weight, and gain muscle. The unique taste and health benefits of Jigarthanda is the only reason that makes this, a perfect cool drink to beat the scorching heat of summer (Jeyashri, 2019).

Functional foods are ingredients that offer health benefits that extend beyond their nutritional value it contains. The effective way of improving health status for all age groups is the regular intake of functional foods. At present, professionals are recognizing that some functional components of foods have a major role in health enhancement. Functional foods are any fresh or processed foods, which have a health-promoting or disease-preventing property other than the basic function of the supply of nutrients. Potential health benefits were offered by functional foods and it could enhance the well-being of consumers and reduce the economic and social costs of treating non-communicable diseases (Das et al., 2010).

Carrot is a root vegetable, which is rich in bioactive compounds like carotenoids and dietary fibers. These are rich in several other functional components having significant health-promoting properties like vitamin K1, potassium, and antioxidants. Since carrot has natural antioxidants and anti-cancer properties, the consumption of carrot and its products is increasing steadily (Sharma et al., 2012).

Palm Jaggery is made from palm juice, a traditional healthy product, prepared without using any chemicals. Minerals are rich in palm jaggery, especially iron (Le et al., 2020). The regular consumption of palm jaggery improves digestive health.

It has been observed that the sweetener present in jaggery activates the digestive enzymes, enhances the regular bowel movement, and cleanses the system. Palm Jaggery, also helps to relieve the most common cold and cough (Singh et al., 2013).

Jigarthanda is a milk-based sweet cool drink. Milk is a complex mixture of specific bioactive proteins, lipids, and saccharides and has several biologically active components (Donovan, 2006).
Except for iron and vitamin C, milk contains all the micronutrients like vitamins and trace elements. It also contains major nutrients like carbohydrates, protein, and fat.

The regular intake of functional components like carotenoids incorporated in food provides more health benefits. Carrot is a good source of carotenoids, vitamins, and dietary fiber (Nicolle et al., 2004). It is also a good source of minerals and antioxidants (Arscott \& Tanumihardjo, 2010). Carotenoids are important micronutrients for human health. (Castermiller \& West, 1998).

The edible portion of carrots contains carotenoids range from 6,000 to $54,800 \mu \mathrm{g} / 100 \mathrm{~g}$ (Simon \& Wolff, 1987). The carotenoids are a precursor of vitamin $\mathrm{A}$ and it has been linked with the improvement of the immune system (Nocolle et al., 2003) and reduce risk of degenerative diseases like cancer, CVD, age-related macular degeneration, cataract formation (Ranganna, 1993), and Alzheimer's disease (Zaman et al., 1992).

Usually, to make Jigarthanda, a sweet drink, cane sugar is added with milk during Jigarthanda preparation. Instead of white cane sugar, the addition of palm jaggery provides the nutrient iron. Palm jaggery is a more nutritious sap based product providing numerous health benefits. It contains $1.04 \%$ protein, $0.19 \%$ fat, $76.86 \%$ sucrose, $1.66 \%$ glucose, $3.15 \%$ total minerals, $0.861 \%$ calcium, $0.052 \%$ phosphorus, $11.01 \%$ iron and $0.767 \%$ copper (Morton, 1988). Almond gum can be dissolved in water and is used in making jellies, health drinks, milkshakes, etc. Almond gum has the role of an emulsifier, stabilizer, and texturing additive which has been utilized by the food and pharmaceutical industries.

Since Jigarthanda has been one of the favorite delicious drinks for all the age groups, the present study focuses on the acceptability of the functional drink Jigarthanda with the incorporation of low cost, locally available functional food ingredients carrot and palm jaggery along with the basic ingredients. The present study was carried out with the aim of (i) formulation of value-added functional drink Jigarthanda and (ii) evaluation of the acceptability of the formulated functional drink Jigarthanda.

\section{Materials and Methods}

\subsection{Procurement of raw materials}

For the formulation of Jigarthanda, Fresh standard milk (Fat 4.5 \& SNF 8.5), almond gum, and palm jaggery were procured from the departmental store located in Madurai. The carrot was purchased from the local market, Madurai. The ingredients used for preparing the Jigarthanda drink have a cooling effect on the system (Sailu, 2015). 
Table 1 Proportions of the Ingredients used for the Functional drink Jigarthanda

\begin{tabular}{|ccccccc|}
\hline & \multicolumn{2}{c}{ Variation- I } & \multicolumn{2}{c|}{ Variation- II } & \multicolumn{2}{c|}{ Variation- III } \\
Ingredients & Proportion A & Proportion B & Proportion A & Proportion B & Proportion A & Proportion B \\
\hline Full Cream Milk & 1 Liter & $1 \mathrm{Liter}$ & 1 Liter & 1 Liter & 1 Liter & 1 Liter \\
\hline Palm Jaggery & $100 \mathrm{~g}$ & $100 \mathrm{~g}$ & $150 \mathrm{~g}$ & $150 \mathrm{~g}$ & $250 \mathrm{~g}$ & $50 \mathrm{~g}$ \\
\hline Milk Kova & $50 \mathrm{~g}$ & $50 \mathrm{~g}$ & $50 \mathrm{~g}$ & $50 \mathrm{~g}$ & $50 \mathrm{~g}$ & $200 \mathrm{ml}$ \\
\hline Carrot Juice & $100 \mathrm{ml}$ & $200 \mathrm{ml}$ & $100 \mathrm{ml}$ & $200 \mathrm{ml}$ & $100 \mathrm{ml}$ & $200 \mathrm{~g}$ \\
\hline Almond Gum & $200 \mathrm{~g}$ & $200 \mathrm{~g}$ & $200 \mathrm{~g}$ & $200 \mathrm{~g}$ & $200 \mathrm{~g}$ & $200 \mathrm{~g}$ \\
\hline
\end{tabular}

Table 2 Sensory Evaluation of Formulated Functional Drink Jigarthanda

\begin{tabular}{|c|c|c|c|c|c|}
\hline \multirow{2}{*}{$\begin{array}{l}\text { Functional } \\
\text { Drink Jigarthanda }\end{array}$} & \multirow{2}{*}{ Factors } & \multicolumn{2}{|c|}{$\begin{array}{c}\text { Proportion A } \\
\text { (Carrot Juice-100 ml) }\end{array}$} & \multicolumn{2}{|c|}{$\begin{array}{c}\text { Proportion B } \\
\text { (Carrot Juice-200 ml) }\end{array}$} \\
\hline & & Percentage & Mean Value & Percentage & Mean Value \\
\hline \multirow{6}{*}{ Variation I } & Appearance & 83.3 & 7.5 & 83.3 & 7.5 \\
\hline & Colour & 85.0 & 7.65 & 85.5 & 7.7 \\
\hline & Consistency & 84.4 & 7.6 & 82.2 & 7.4 \\
\hline & Taste & 83.3 & 7.5 & 82.2 & 7.4 \\
\hline & Flavor & 80.0 & 7.2 & 80.0 & 7.2 \\
\hline & Overall Acceptability & 76.6 & 6.9 & 77.7 & 7.0 \\
\hline \multirow{6}{*}{ Variation II } & Appearance & 84.4 & 7.6 & 83.3 & 7.5 \\
\hline & Colour & 85.0 & 7.65 & 86.1 & 7.75 \\
\hline & Consistency & 83.3 & 7.5 & 81.6 & 7.35 \\
\hline & Taste & 85.0 & 7.65 & 86.1 & 7.75 \\
\hline & Flavor & 80.5 & 7.25 & 81.1 & 7.3 \\
\hline & Overall Acceptability & 77.7 & 7.0 & 79.4 & 7.15 \\
\hline \multirow{6}{*}{ Variation III } & Appearance & 84.4 & 7.6 & 84.4 & 7.6 \\
\hline & Colour & 86.1 & 7.75 & 87.2 & 7.85 \\
\hline & Consistency & 83.3 & 7.5 & 82.2 & 7.4 \\
\hline & Taste & 88.8 & 8.0 & 89.4 & 8.05 \\
\hline & Flavor & 80.5 & 7.25 & 80.5 & 7.25 \\
\hline & Overall Acceptability & 80.8 & 7.27 & 81.1 & 7.3 \\
\hline
\end{tabular}

\subsection{Preparation of carrot juice}

Carrot Juice was prepared from orange color highly nutritious fresh carrots. It is rich in $\alpha$ and $\beta$-carotene, B-vitamins, folate, calcium, magnesium, potassium, copper, and iron (Schieber \& Weber, 2016). The process starts with the carrots being scrubbed; washed and sorted (any damaged carrots are removed). The carrots are shredded and the juice was pressed out of the shredded carrots (Davis \& Waldron, 2010) in the food processor or blender. A puree was made by adding small amounts of water to the carrots and giving them a nice stir. It is kept for 15-20 minutes and this will boost its nutrient properties. Finally, the juice was strained through a hand strainer (Karanreed, 2018).

\subsection{Preparation of Almond gum}

5 grams of almond gum was taken and soaked in 1 liter of water for 8 hours / overnight. It almost increased 10 times in volume. It absorbed all the water and turned transparent like a jelly. It was refrigerated until use.

\subsection{Formulation \& standardization of jigarthanda}

Initially, three variations of the cold beverage Jigarthanda were prepared. The proportion of the various ingredients used for preparing the functional drink Jigarthanda is tabulated in Table 1. Jigarthanda has been prepared by the procedure given by Jeyashri (2019). One liter of full cream milk was taken in a stainless steel pan and boiled on high flame. To this, $100 \mathrm{~g} / 150 \mathrm{~g} / 250 \mathrm{~g}$ of palm jaggery were added in the variations combinations such as VI, VII, and VIII. It was stirred until dissolved. The full-fat milk was reduced by slowly boiling the milk until it thickened and reduced to almost half of its original quantity. The color of the reduced milk which was light brown gave Jigarthanda drink its unique color and flavor. The sides are scraped every 5 minutes to collect the cream from the milk. Then 50 grams of sweet less milk Kova was added into all three variations and then $100 \mathrm{ml} / 200 \mathrm{ml}$ of carrot juice was added into VI, VII, and VIII. This was heated for just 5 to10 minutes and refrigerated until chilled for 4-5 hours. Then $200 \mathrm{ml}$ of soaked almond gum was added into all the three Variations of prepared Jigarthanda and then stored at refrigerator temperature. 


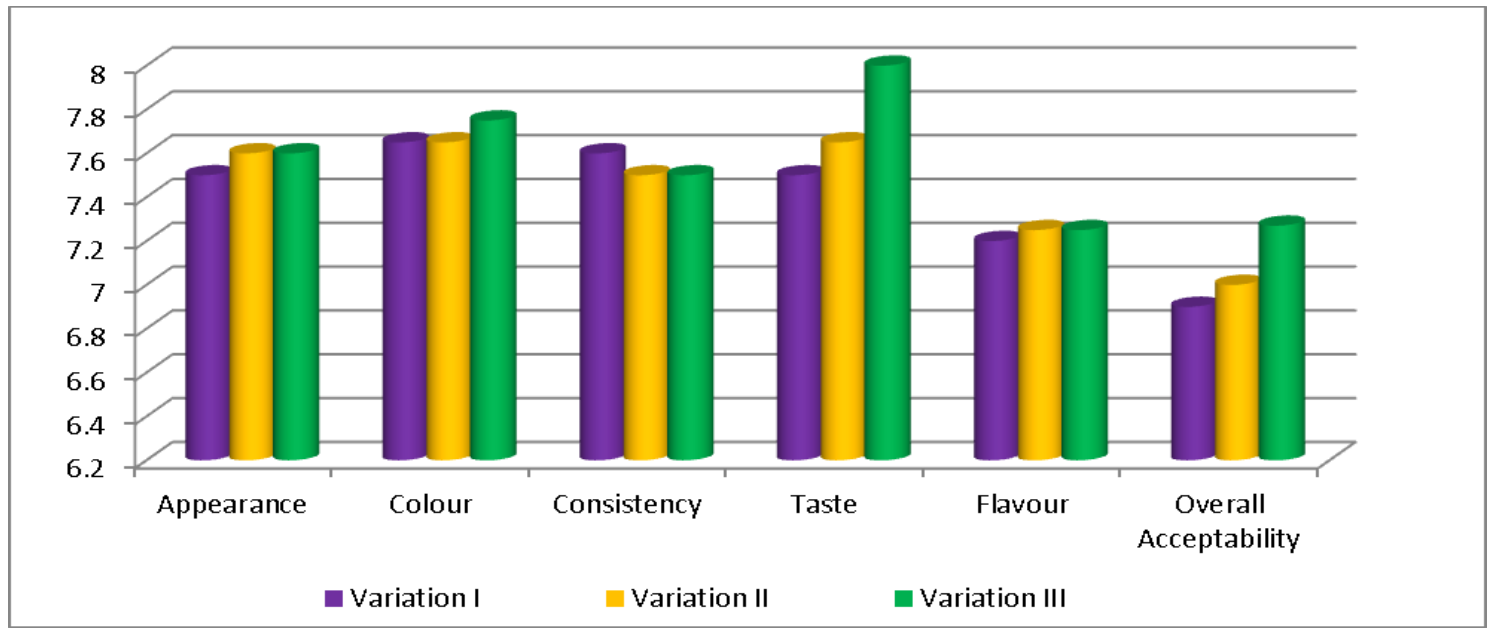

Figure 1: Sensory Evaluation of Formulated Functional Drink Jigarthanda Proportion A (Carrot Juice-100 ml)

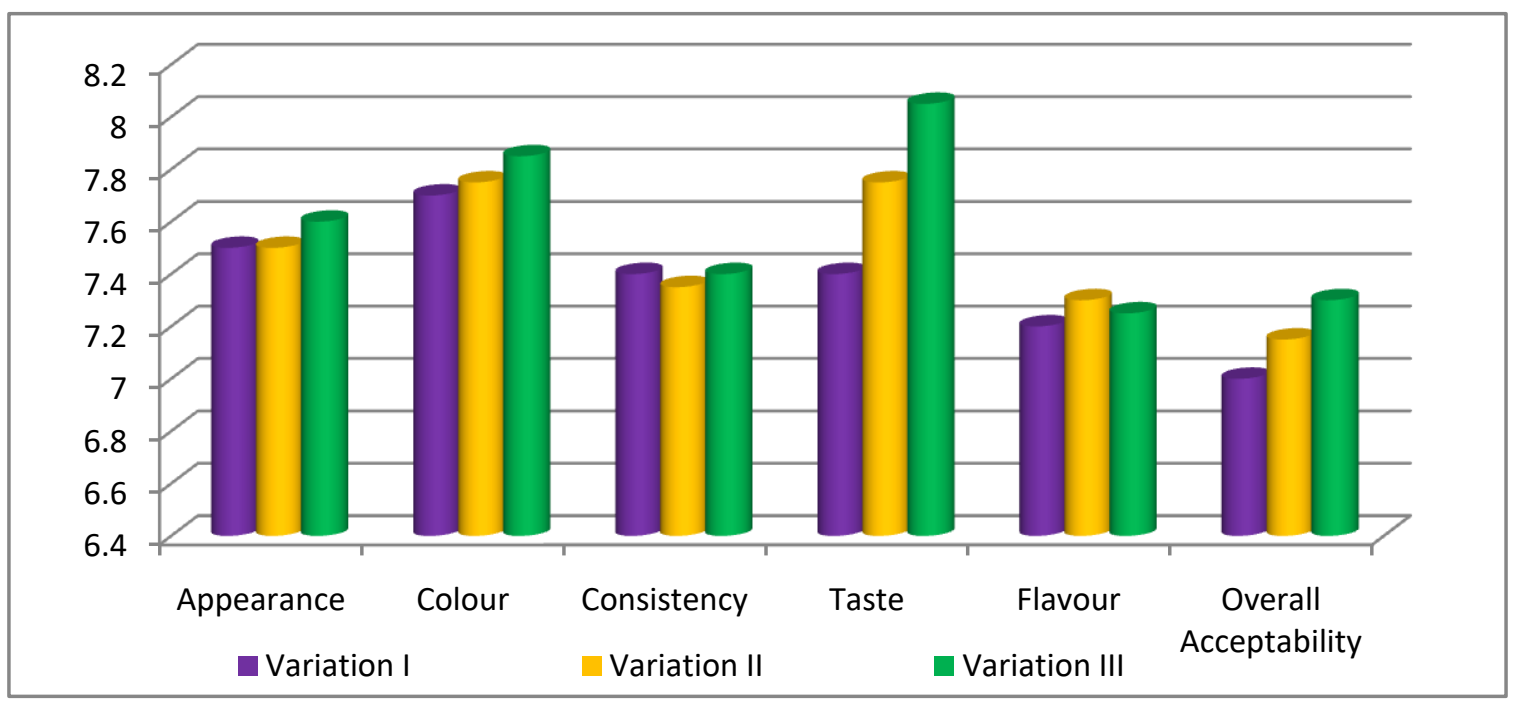

Figure 2: Sensory Evaluation of Formulated Functional Drink Jigarthanda Proportion B (Carrot Juice-200 ml)

2.5 Sensory evaluation of formulated functional drink Jigarthanda

Sensory science is "a scientific discipline used to evoke, measure, analyze, and interpret reactions to meat sensory characteristics as perceived by the senses of sight, smell, touch, taste, and hearing" (Miller, 2001). The sensory attributes of the Jigarthanda namely appearance, color, consistency, taste, flavor, overall acceptability was evaluated using a nine-point hedonic scale as described by Ranganna (1993). The scoring was allotted from 9 to 1 respectively like extremely, like very much, like moderately, like slightly, neither like nor a dislike, dislike slightly, dislike moderately, dislike very much and dislike extremely.

Three variations were prepared separately and the products were subjected to the same methods of sensory evaluation. A nine-point hedonic scale scorecard was provided to the panelists to adjudge the quality of the product prepared by three different variations concerning the appearance, color, consistency, taste, flavor, and overall acceptability.

\section{Results}

Sensory Evaluation deals with analyzing and interpreting the qualities of food as they are perceived by the sense of appearance, color, flavor, consistency, taste, flavor, overall acceptability. Sensory evaluation is designed to reflect common preferences and to maintain the quality of food at a given standard condition. All three variations of the functional drink were prepared by using $100 \mathrm{~g}, 150 \mathrm{~g}$, and $250 \mathrm{~g}$ of palm jaggery having two different concentrations of carrot juice viz., A (100ml) and B (200ml), and each was tested by a panel of 20 members. 
The panel evaluated the formulated functional drink Jigarthanda for its sensory attributes namely appearance, color, consistency, taste, flavor, and overall acceptability. The findings are given in table 2 and also given in chart $1 \& 2$, which exhibits the overall ranking score for the formulated functional drink Jigarthanda in different proportions. Among the three variations, Variation I was marked high for all the studied factors with a mean value of 7 in both Proportion A and B, except the overall acceptability of Proportion A has a mean value below 7. While for Variation II and in Variation III, all the factors in both proportions A and B were marked as high with a mean score of more than 7 and particularly in variation III, the taste factor got a high mean score of more than 8 and the overall acceptability was very high in Proportion B and the mean score was 7.3, which was more than proportion A (7.27) but not statistically different. The results of the present study correlate with a similar study conducted on the acceptability of carrot powder and wheat flour mixed biscuit, evaluated in terms of color, flavor, texture, and overall acceptability by taste panel members. As per the sensory analysis, it was found that the biscuit incorporated with $6 \%$ carrot powder had maximum acceptability comparatively control (Mounika \& Maloo, 2018). According to Phoebean et al. (2017), the biscuits incorporated with carrot powder and cowpea flour enrich the biscuit value and increasing the protein and carotenoid contents. Boland (2010) revealed that the incorporation of $20 \%$ carrot in paneer showed the highest acceptability by the panelists. The proximate analysis demonstrated that the formulated product was rich in nutritional values when compared to pure cow milk paneer. Also, it was suggested that the incorporation of natural products such as carrot in paneer can be used as a better source to enhance nutrition.

\section{Discussion}

Jigarthanda, being one of the delicious milk-based favorite drink of all age groups, was chosen to incorporate it with functional foods, to make it a value-added drink. The value addition in Jigarthanda seemed to be one of the best ways to improve human health status. Nutrient-rich generally available foods have been selected and incorporated to provide a functional drink to fulfill the nutrien demands of individuals. Carrot is rated tremendously high among vegetable foods when correctly utilized. It is a commendable source of a considerable quantity of carotenoids and other nutrients. Subsequently, in the current study, an attempt was made to formulate carrot juice and palm jaggery incorporated Jigarthanda to make it an enhanced nutritional value-added drink.

Sensory evaluation is a significant feature that reciprocates with taste, aroma, and visual appearance which includes the sensory attributes of foods. The only way to evaluate sensory characteristics by the grades of intuition experienced by a human being was by judging food which is attributed to the decision of the consumer. The study revealed that the functional drink Jigarthanda in VIII of Proportion B, which was made with 250 grams palm jaggery, incorporated with $200 \mathrm{ml}$ of carotenoid-rich carrot juice obtained the highest overall acceptability score that was regarded as the best sensory evaluated variation of Jigarthanda.

\section{Conclusion}

In the present study, the sensory evaluation was analyzed ant it elicited that carrot and Palm Jaggery incorporated functional drink Jigarthanda was of high priority, in terms of sensory attributes like appearance, texture, and taste. Besides, it proved to be a nutrientpacked favorite milk-based drink Jigarthanda. Thus the popular traditional beverage Jigarthanda has been value-added to provide carotenoid, an irreplaceable nutraceutical, which can be commercialized to children and adults, the most likely consumers.

\section{Recommendation}

As Jigarthanda is a very popular delicious drink, more research on this product can make this nutritious drink available to the common man. Some suggestions for further studies (i) The formulated value-added Jigarthanda with the highest acceptability can be subjected to further study on shelf life, packaging methods, and cost analysis (ii) Analyze the nutritive value of the formulated functional drink Jigarthanda.

\section{Acknowledgment}

The study is a part of an ongoing Ph.D. thesis on Standardization Shelf life Evaluation of Functional Food Products from Specific Millets, Dairy, and Fruits. The authors would like to thank the Madurai Kamaraj University, Madurai, Tamil Nadu, India, and their working institutions for their support rendered in carrying out the research work.

\section{References}

Arscott SA, Tanumihardjo SA (2010) Carrots of many colors provide basic nutrition and bioavailable phytochemicals acting as a functional food. Comprehensive Reviews in Food Science and Food Safety 9:223-239.

Boland M (2010) 'Designer' milk: Functional foods from milk; improving the safety and quality of milk, Wood Head Publishing Series in Food Science. Technology and Nutrition 12010:74-93.

Castermiller JM, West CE (1998) Bioavailability and bioconversion of carotenoids. Annual Review of Nutrition 18:1938.

Das DR, Vimala, Das N (2010) Functional foods of natural origin - An overview. Indian Journal of Natural Products and Resources 1(2):136-142. 
Davis JK, Waldron (2010) Case Studies in Novel Food Processing Technologies. Wood head Publishing Limited, Cambridge, UK.

Donovan SM (2006) Role of human milk components in gastrointestinal development: Current knowledge and future needs. Journal of Paediatrics 149:S49-S61.

Jeyashri (2019) Famous Jigarthanda - The real Jigarthanda drink in Madurai. Available from: https://threewhistleskitchen.com/madurai-jigarthanda-recipe/ [July 24, 2019]

Karanreed (2018) How to make carrot Juice (step by step guide). Available from https://www.positivehealthwellness.com/recipes/how-to-makecarrot-juice-step-by-step-guide/ Access on March 22, 2018.

Le DHT, Lu W, Li PH (2020) Sustainable processes and chemical characterization of natural food additives: Palmyra Palm (BorassusFlabellifer Linn.) Granulated Sugar. Sustainability 12(7): 2650 .

Miller RK (2001) Lawrie's Meat Science, Eighth Edition A volume in Wood head Publishing Series in Food Science, Technology and Nutrition Book.

Morton JF (1988) Notes on distribution, propagation, and products of Borassus palms (Arecaceae). Economic Botany 42(3):420-441.

Mounika G, Maloo S (2018) Development and sensory evaluation of biscuit by incorporation of carrot powder. International Journal of Current Microbiology and Applied Science 7(4): 2583-2592.

Nicolle C, Simon G, Rock E, Amouroux P, Rémésy C (2004) Genetic variability influences carotenoid, vitamin, phenolic, and mineral content in white, yellow, purple, orange, and dark-orange carrot cultivars. Journal of the American Society for Horticultural Science129:523-529.
Nocolle C, Cardinault N, Aprikian O, Busserolles J, Grolier P, Rock E, Demigne C, Mazur A, Scalbert A, Amouroux P, Remesy C (2003) Effect of carrot intake on cholesterol metabolism and antioxidant status in cholesterol-fed rats. European Journal of Nutrition 42:254-261.

Phebean IO, Akinyele O, Toyin A, Folasade O, Olabisi A, Nenna E (2017) Development and quality evaluation of carrot powder and cowpea flour enriched biscuits. International Journal of Food Science and Biotechnology 2(2):67-72.

Ranganna S (1993) Manual Analysis and Quality Control for fruits and Vegetable Products Tata McGraw Hill Co Ltd., New Delhi 869-923.

Sailu (2015) Jigarthanda a special recipe for Madurai. Available from: https://www.sailufood.com/jigarthanda-recipe-special-drinkmadurai/[June 19, 2015]

Schieber A, Weber F (2016) Handbook on Natural Pigments in Food and Beverages. Woodhead publishing is an imprint of Elsevier, UK

Sharma KD, Karki S, Thakur NS, Attri S (2012) Chemical composition, functional properties, and processing of carrot - a review. Journal of Food Science and Technology 49(1):22-32.

Simon PW, Wolff XY (1987) Carotene in typical and dark orange carrots. Journal of Agricultural and Food Chemistry. 35:10171022.

Singh J, Solomon S, Kumar D (2013) Manufacturing Jaggery, a Product of Sugarcane, As Health Food. Agrotechnology S11:007.

Zaman Z, Roche S, Fielden P, Frost PG, Nerilla DC, Cayley ACD (1992) Plasma the concentration of vitamin A and E and carotenoids in Alzheimer's disease. Age Ageing 21:91-96.

Journal of Experimental Biology and Agricultural Sciences http://www.jebas.org 